\title{
Ligand Effect on the Growth and the Digestion of Co Nanocrystals
}

\author{
Anna C. S. Samia et al. \\ Supporting Materials
}

1) Experimental section.

2) Figure S1. ESI-MS spectra of cobalt cluster complex under different fragmentation voltages and in different carrier solvents

3) Figure S2. ESI-MS spectra of Fe cluster complex using methanol as carrier solvent

4) Figure S3. TEM images of $9.5 \mathrm{~nm}$ cobalt nanoparticles.

5) Figure S4. Magnetic properties of cobalt nanoparticles and cobalt clusters.

\section{1) Experimental Section:}

All the syntheses and post reaction processing were carried out in an argon atmosphere using a standard glove box and Schlenk line techniques. Octacarbonyldicobalt containing 1-5\% hexane as a stabilizer was purchased from Alfa Aesar. The hexane was evaporated by leaving the bottle open inside the argon dry box. Iron pentacarbonyl (99.999\%), oleic acid (99+\%) (OA), trioctylphosphine oxide (99\%) (TOPO), anhydrous 1,2-dichlorobenzene (99\%), anhydrous methanol (99.8\%), 1.0 M lithium aluminum hydride (LAH) in diethyl ether, platinum acetylacetonate (99.99\%), 1,2-hexandecanediol (90\%) were purchased from Aldrich and used as received. Octacarbonyldicobalt and iron pentacarbonyl are highly flammable and the thermal decomposition of these materials release carbon monoxide, which is toxic upon inhalation. Therefore, the reactions were carried out in a well ventilated hood. Glassware were cleaned in acid and base bath before thoroughly rinsed with deionized water and dried in oven. Any residue remained on the glass, especially on the condenser, will cause inhomogeneous nucleation of the particle and lead to bimodal particle distribution.

Synthesis: Reaction in path (a) starts by fully dissolving $0.54 \mathrm{~g}$ (1.58 mmol) $\mathrm{Co}_{2}(\mathrm{CO})_{8}$ in $3 \mathrm{~mL}$ 1,2-dichlorobezene to form solution A. $0.1 \mathrm{~g}(0.25 \mathrm{mmol})$ TOPO and $0.2 \mathrm{~mL}(0.63 \mathrm{mmol})$ of oleic acid were dissolved in $15 \mathrm{~mL} 1,2-$ dichlorobenzene to form solution $\mathrm{B}$. After heating solution $\mathrm{B}$ in a $50 \mathrm{~mL}$ flask to $180^{\circ} \mathrm{C}$ under argon flow, solution A (at room temperature) was injected using a syringe. Upon injection, the solution cools to $130^{\circ} \mathrm{C}$ and the mixture was vigorously stirred at this temperature for one hour to allow particle growth. It was found that maintaining the growth temperature at $130^{\circ} \mathrm{C}$ allows the large particles to grow more uniformly, in contrast to the case in which the growth-stage temperature was raised back to $180^{\circ} \mathrm{C}$. The as-prepared nanocrystals are 
transferred to the argon dry box, and precipitated by adding $50 \mathrm{~mL}$ anhydrous methanol and dried under vacuum. The elemental analysis of the precipitated nanocrystals was done at Galbraith Laboratory, Inc. The result is carbon 9.43\%, hydrogen $1.51 \%$ and cobalt $89.47 \%$.

Reaction in path (b) is identical to path (a), except the amount of oleic acid added is $2.5 \mathrm{~mL}(7.87 \mathrm{mmol})$. The temperature of the reaction was kept at $180^{\circ} \mathrm{C}$ and the reaction was allowed to proceed for at least half an hour. The obtained blue solution is stable for several days before start to crystallize.

Reaction in path (c) starts with dissolving precipitated cobalt nanocrystals in $18 \mathrm{~mL}$ of 1,2 -dichlorobenzene, followed by addition of $2.5 \mathrm{~mL}$ of oleic acid. The solution was then heated at $180^{\circ} \mathrm{C}$ on the Schlenk line under argon flow. The color of the solution gradually changes to blue after 5 hours.

Reaction in path (d) was achieved through adding $7.2 \mathrm{~mL} 1 \mathrm{M}$ solution of LAH in diethyl ether to the cluster complex solution formed in path (b) at $180^{\circ} \mathrm{C}$ and stir for about 15 minutes. The color of solution turns black immediately, indicating nanocrystal formation.

\section{2) ESI-MS spectra of cobalt cluster complex under different fragmentation voltages and in different carrier solvents}

a)

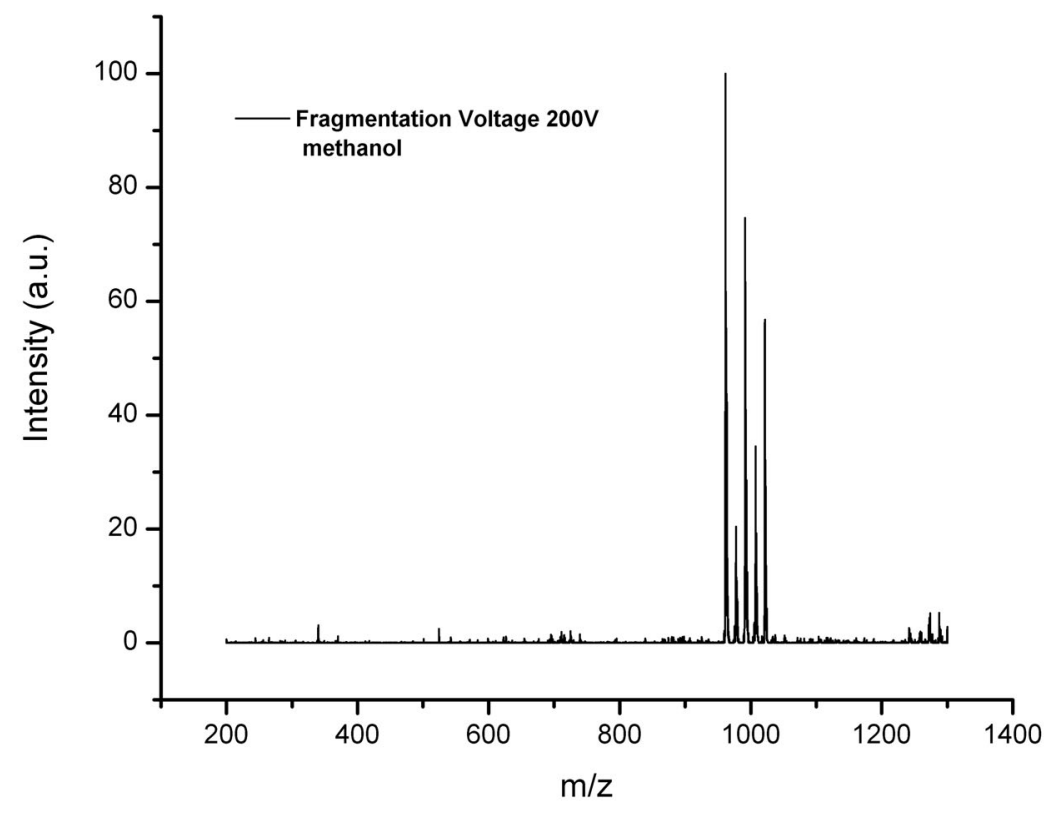


b)

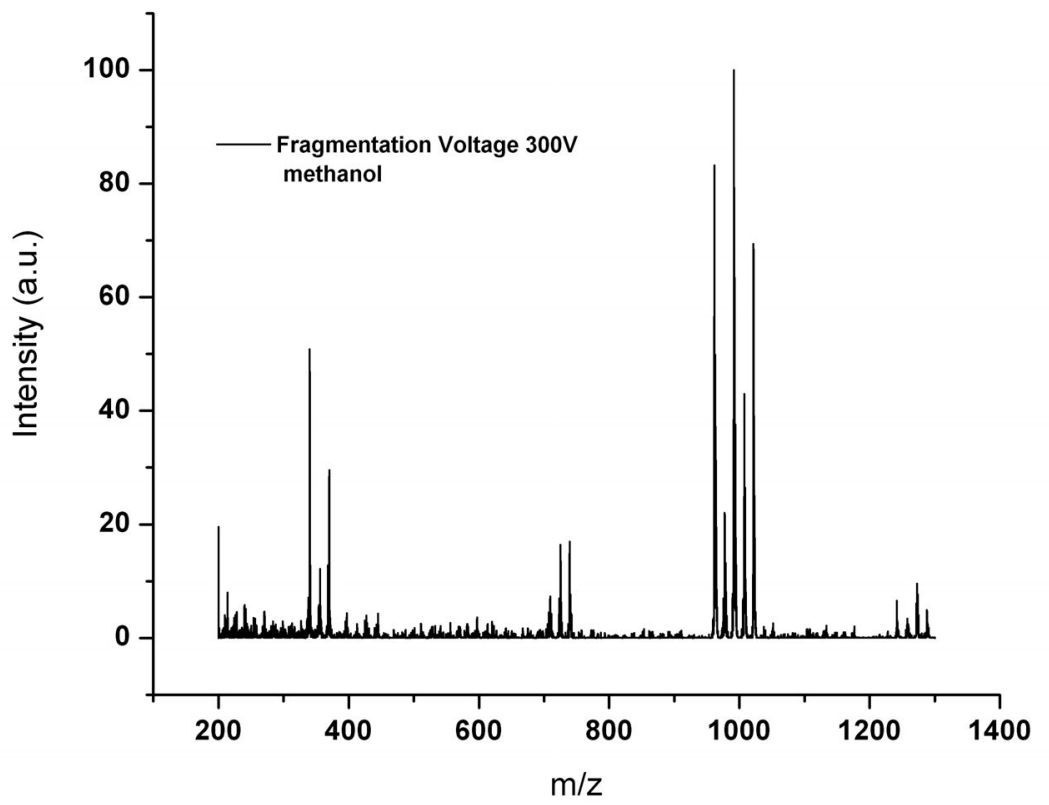

c)

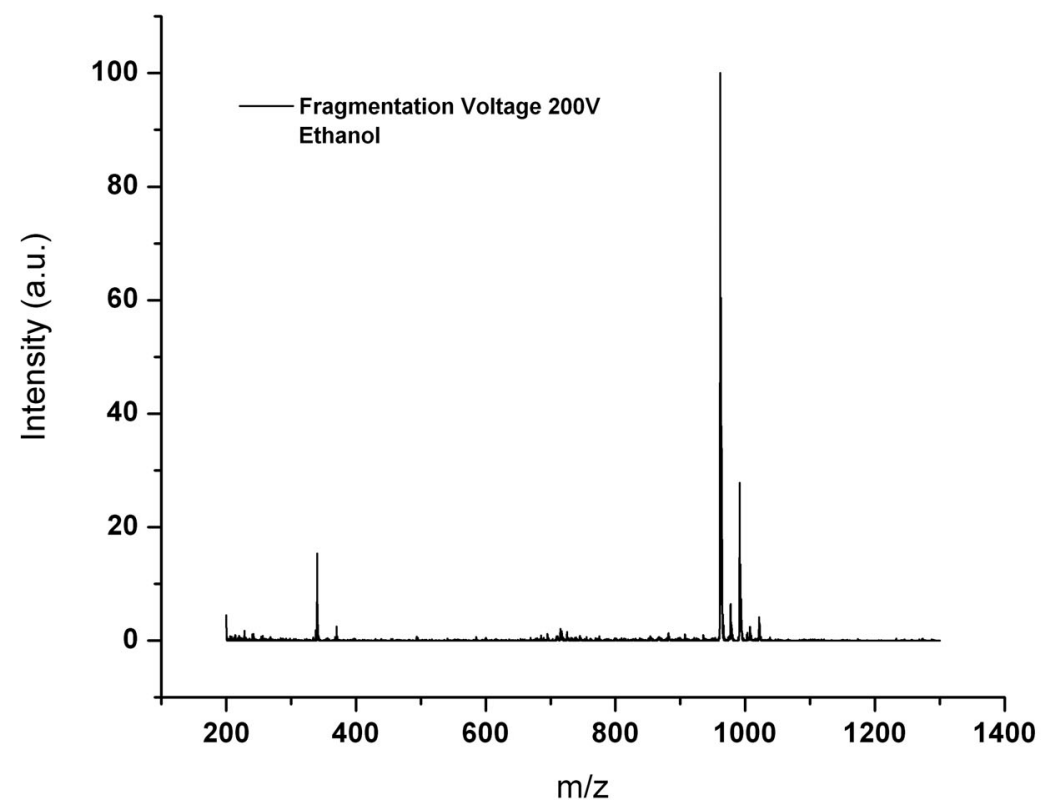


d)

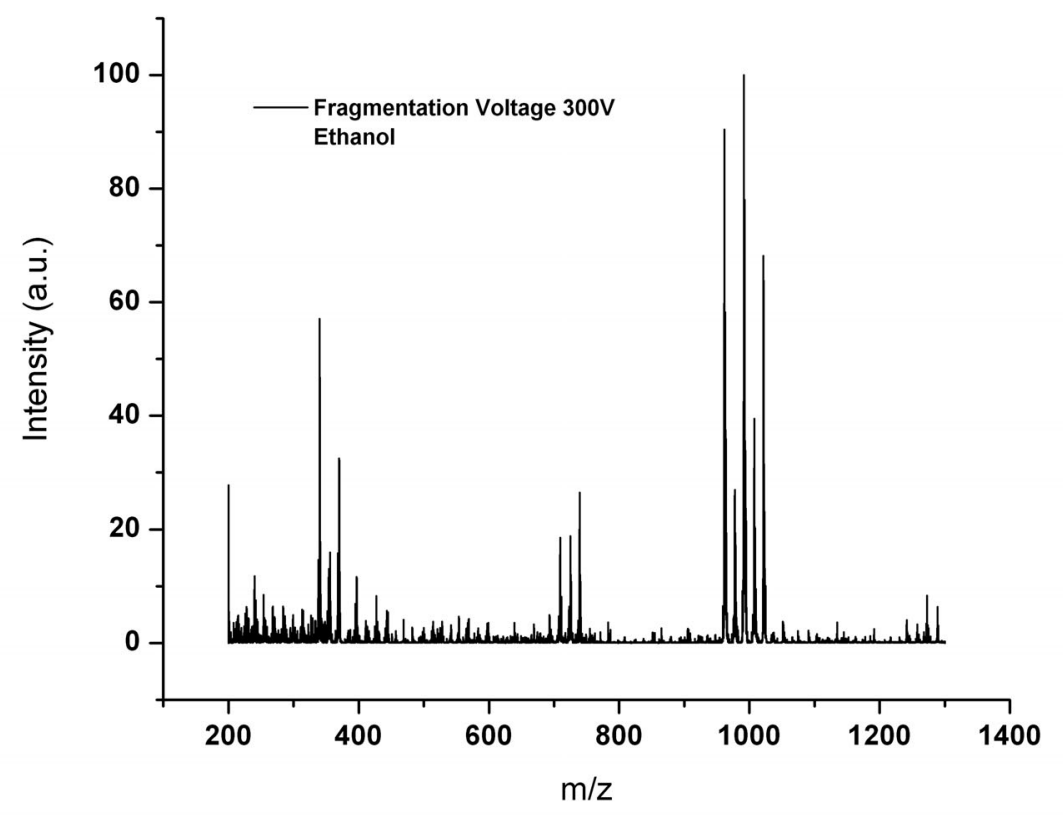

Figure S1. (a)-(d) show ESI-MS data of cobalt cluster solution at different fragmentation voltages using methanol and ethanol as carrier solvents. (a) methanol, 200V. (b) methanol, 300V. (c) ethanol, 200V. (d) ethanol 300V. These experiments further confirmed our conclusion that $\mathrm{Co}_{2}(\mathrm{OA})_{3}$ and $\mathrm{Co}_{3}(\mathrm{OA})_{3}$ are abundant species in the cobalt cluster complex. We also detect small signals of $\mathrm{Co}_{2}(\mathrm{OA})_{4}$ and $\mathrm{Co}_{3}(\mathrm{OA})_{4}$ clusters $(\mathrm{m} / \mathrm{z}$ at 1241-1299) (Figure S1a). With the scan range extended to $\mathrm{m} / \mathrm{z}=2500$, no cluster containing 4 or more cobalt atoms was detected. At high fragmentation voltage, $\mathrm{Co}_{2}(\mathrm{OA})_{2}, \mathrm{Co}_{3}(\mathrm{OA})_{2}$ clusters (m/z at 1241-1299), and $\mathrm{CoOA}(\mathrm{m} / \mathrm{z}$ at 340-370) also appear. In each group, there are several peaks corresponding to either addition of $\mathrm{CO}$ or $\mathrm{O}$ to the cluster. The isotope pattern indicates all these clusters are +1 charged ion. 


\section{3) ESI-MS spectra of Fe cluster complex using methanol as carrier solvent.}

a)

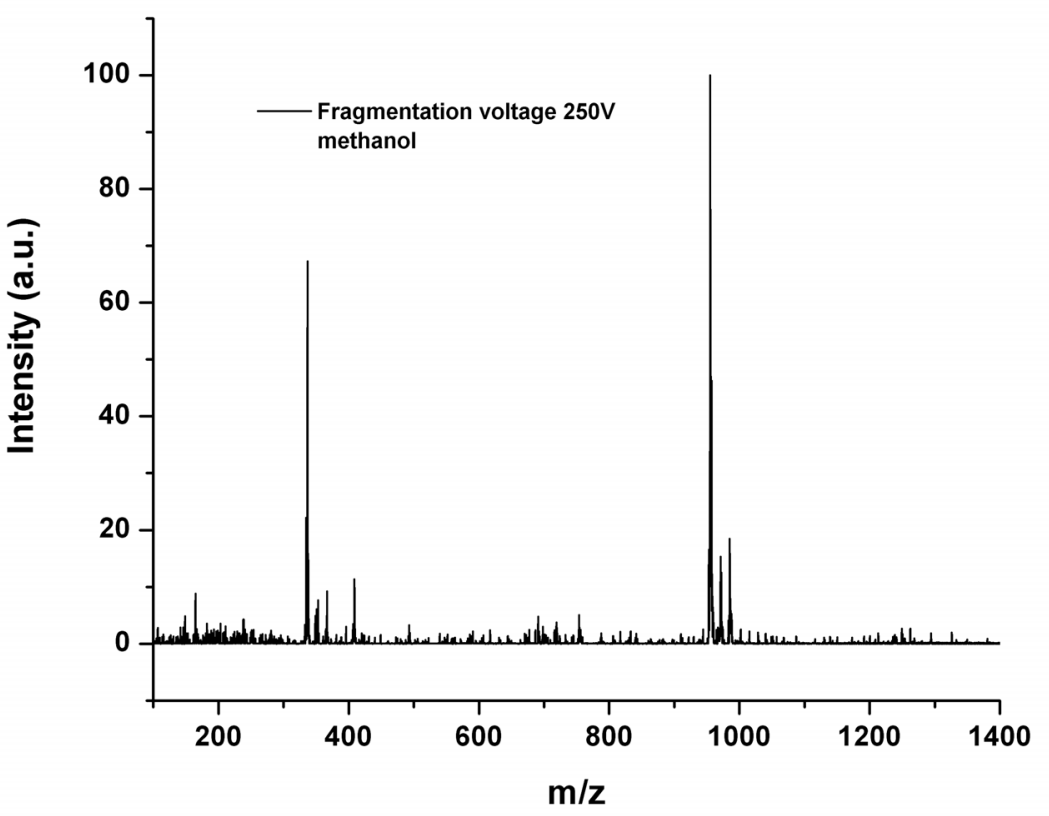

b)

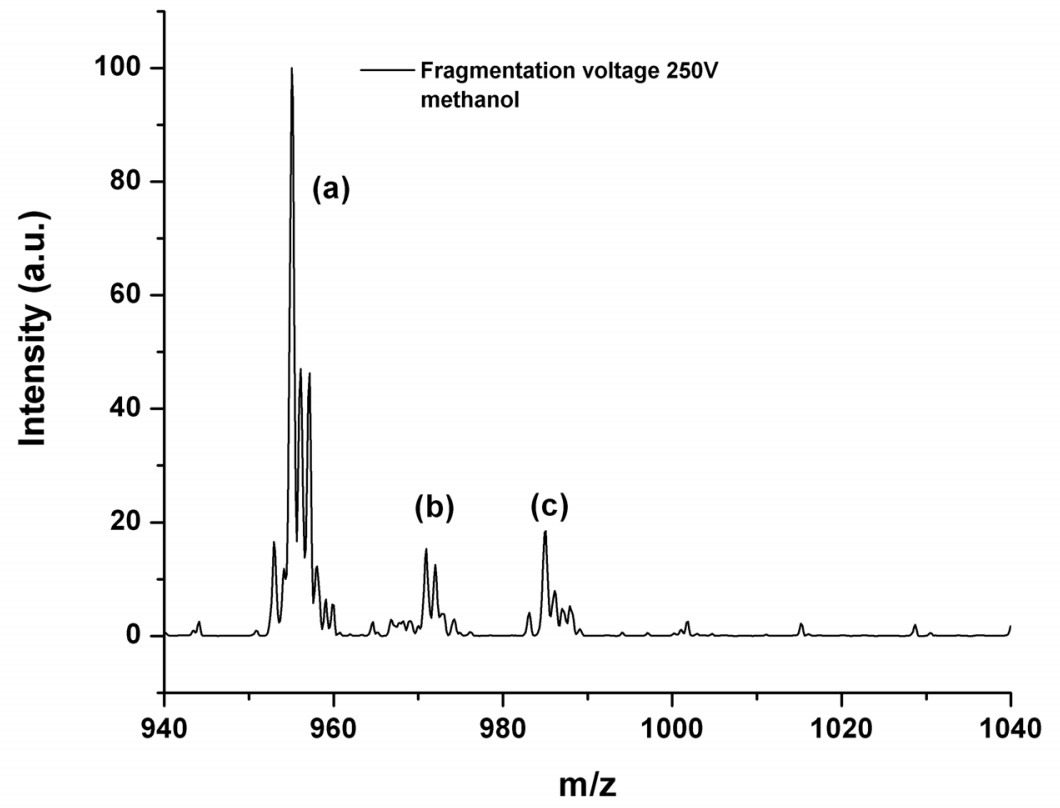

Figure S2. ESI-MS data of Fe cluster solution at $250 \mathrm{~V}$ fragmentation voltages using methanol as carrier solvent. a) two main groups of ions detected are $\mathrm{Fe}_{2}(\mathrm{OA})_{3}(\mathrm{~m} / \mathrm{z}$ at 955-985) and $\mathrm{FeOA}$ clusters (m/z at 337-367). b) zoomed in $\mathrm{Fe}_{2}(\mathrm{OA})_{3}$ region, with mass of each ions correspond to (a) $\left[\mathrm{Fe}(\mathrm{II})_{2}\left(\mathrm{C}_{18} \mathrm{H}_{33} \mathrm{O}_{2}\right)_{3}\right]^{+}, \quad$ (b) $\left[\mathrm{Fe}(\mathrm{II})_{2}\left(\mathrm{C}_{18} \mathrm{H}_{33} \mathrm{O}_{2}\right)_{3} \mathrm{O}\right]^{+}$, (c) $\left[\mathrm{Fe}(\mathrm{I})_{2}\left(\mathrm{C}_{18} \mathrm{H}_{33} \mathrm{O}_{2}\right)_{3} \mathrm{CO}+2 \mathrm{H}\right]^{+}$. 
3) TEM images of $9.5 \mathrm{~nm}$ cobalt nanoparticles.

a)

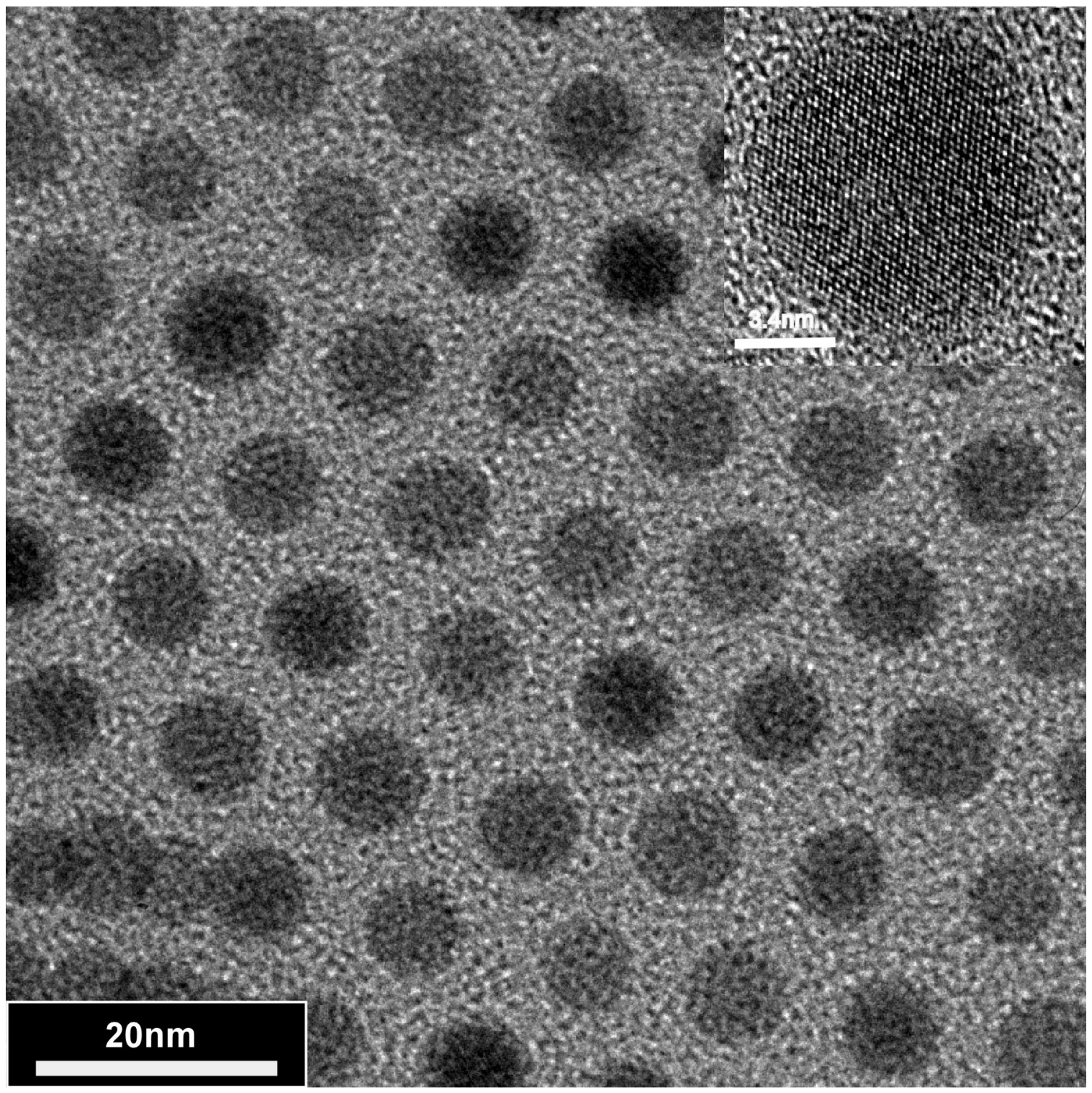


b)

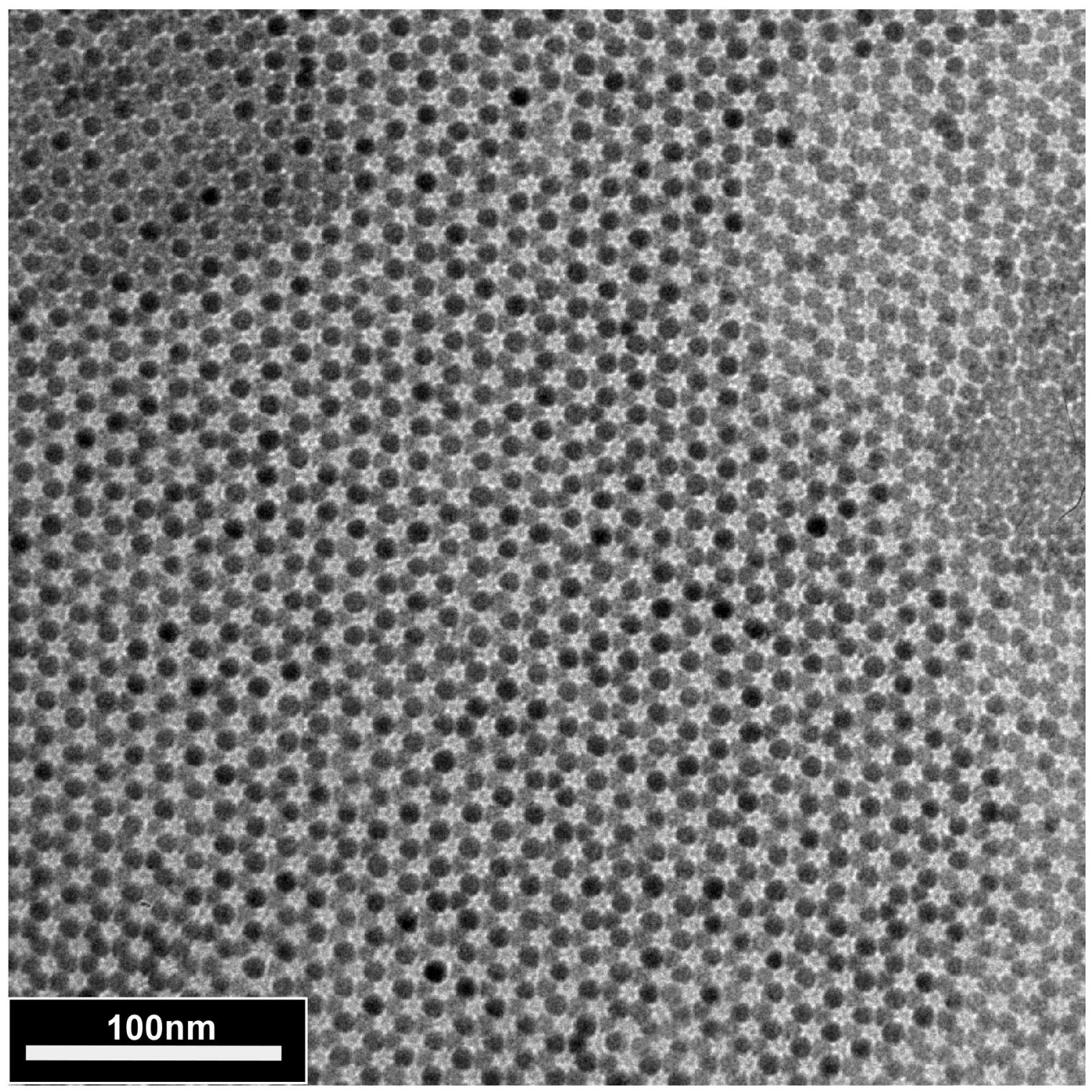

Figure S3. (a) Monolayer of 9.5nm Co nanocrystals, inset shows a high resolution TEM image of a single nanocrystal. (b) Multilayer of $9.5 \mathrm{~nm}$ Co nanocrystals. 
4) Magnetic properties of cobalt nanoparticles and cobalt clusters

a)

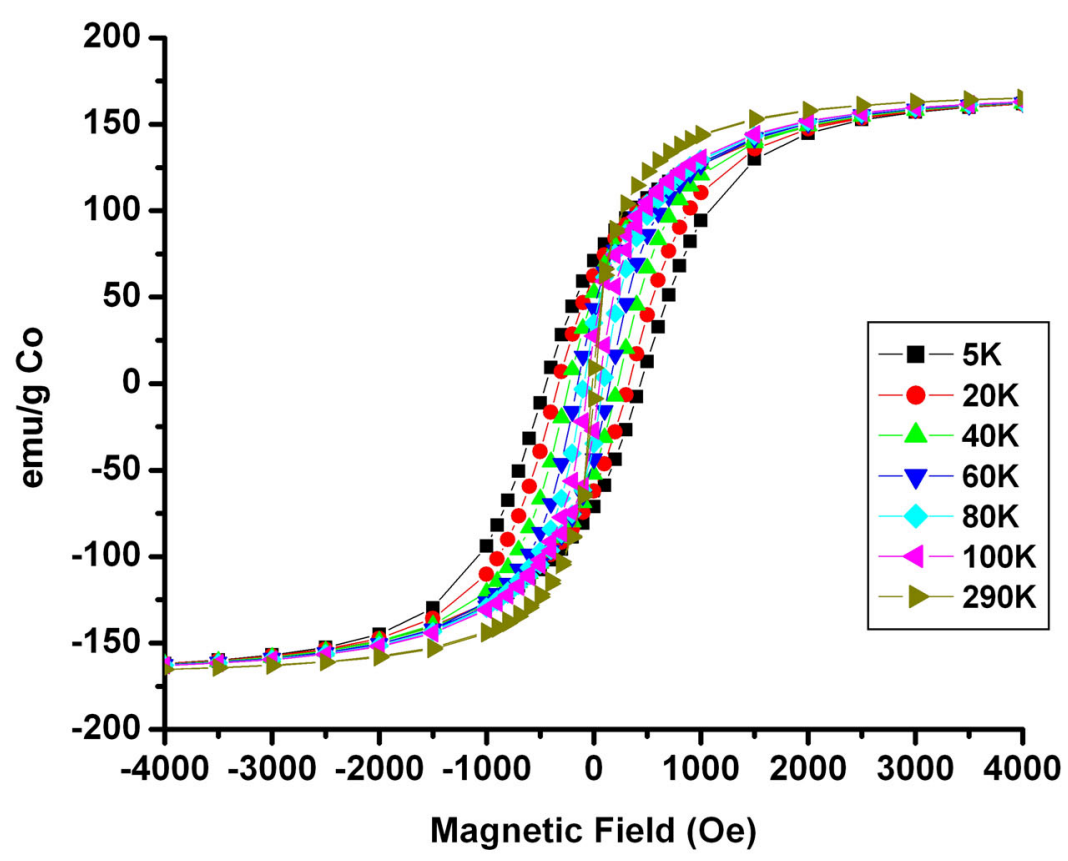

b)

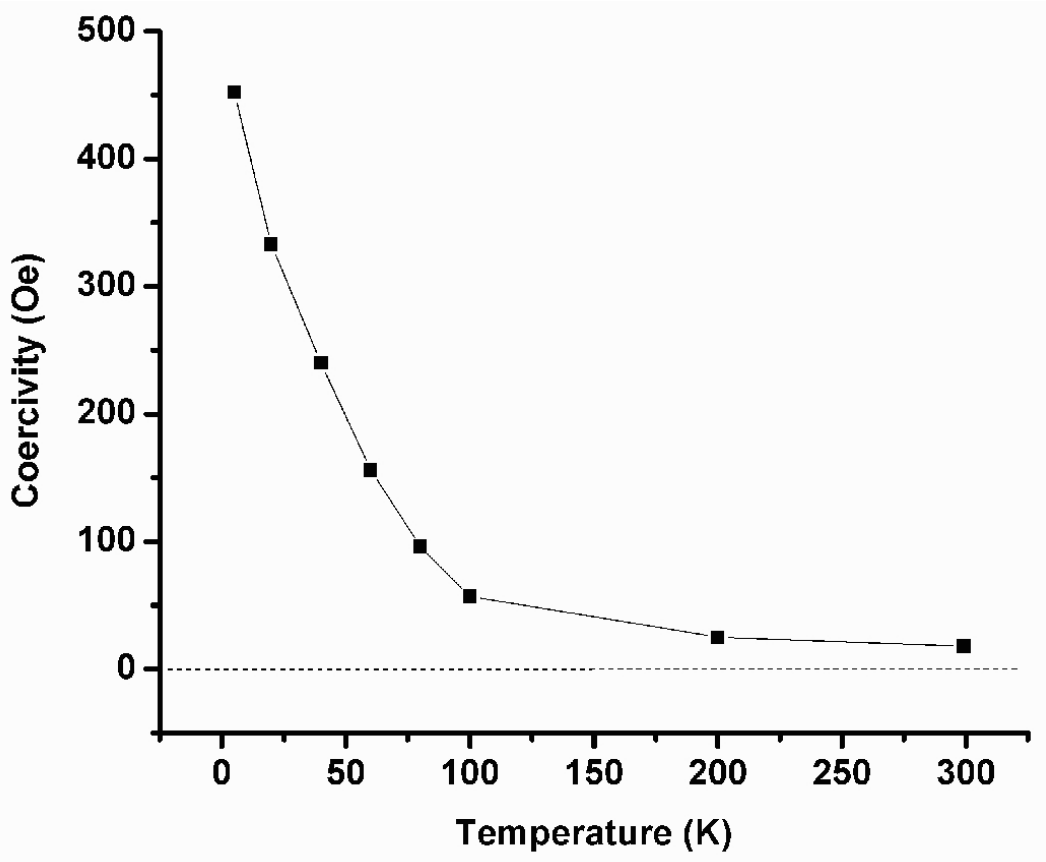


c)

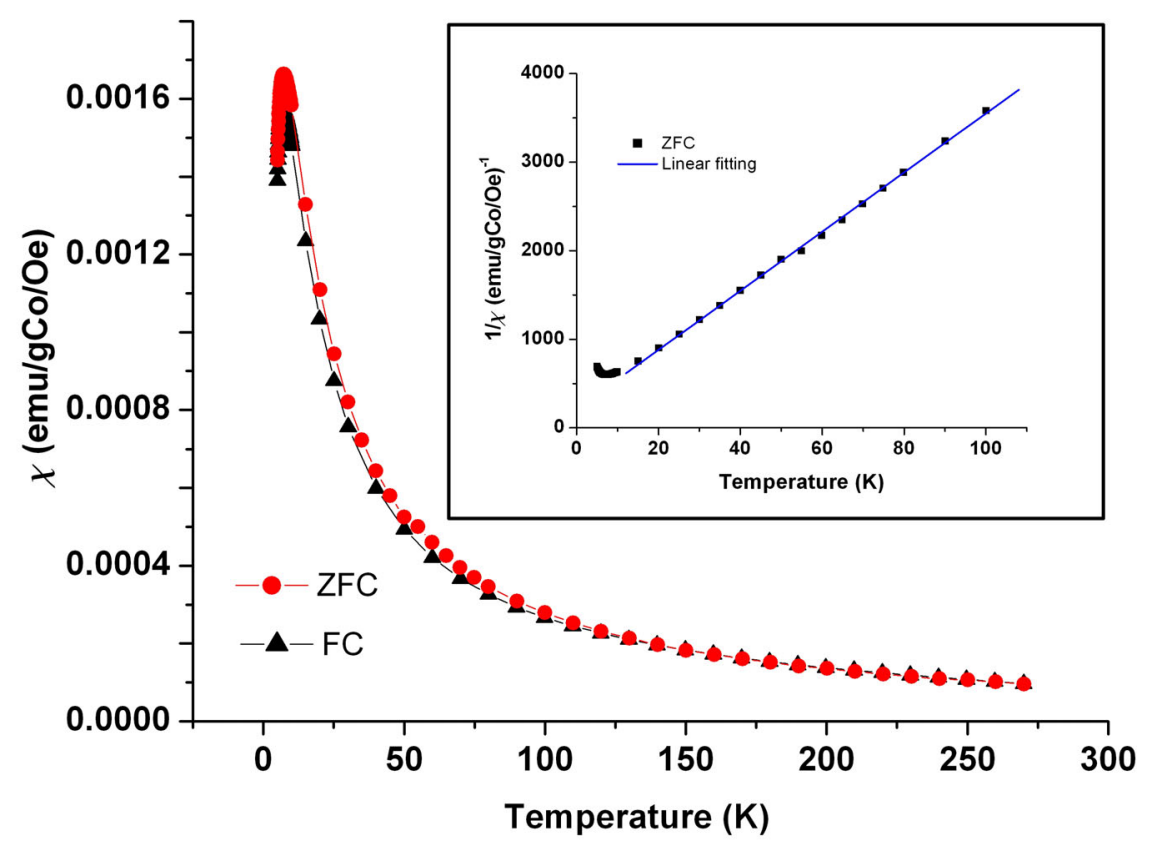

d)

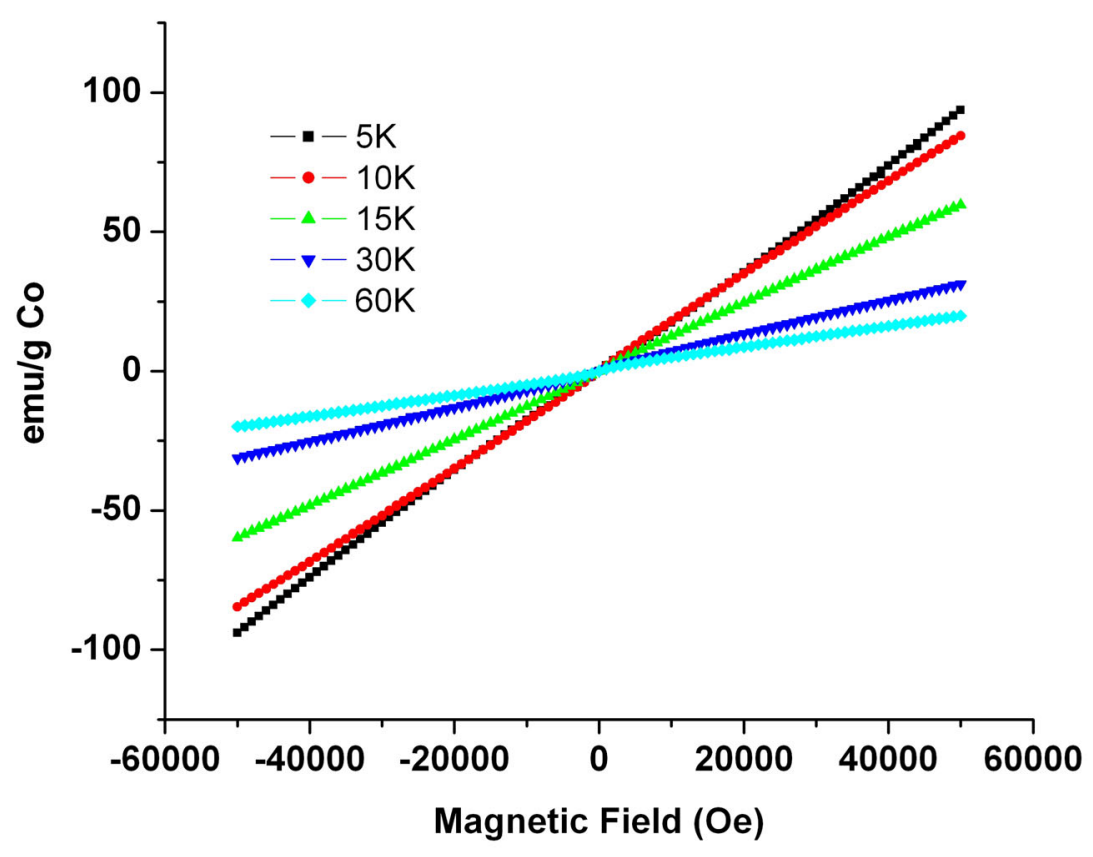

Figure S4. (a)-(b) Magnetic hysteresis loop and coercivity of $9.5 \mathrm{~nm}$ Co nanocrystals at various temperatures. (c)-(d) ZFC-FC susceptibility and magnetic hysteresis loop of cobalt cluster complex at different temperatures. Magnetic interaction between nanocrystals was minimized by diluting the sample with didodecyldimethylammonium bromide (DDAB) surfactant. These measurements show these nanocrystals are ferromagnetic near room temperature with magnetic moments of cobalt close to the bulk 
value. Magnetic measurements on cobalt clusters were measured on precipitated polycrystalline solid, which shows a peak at $7 \mathrm{~K}$ for both $\mathrm{ZFC}$ and $\mathrm{FC}$ measurement. This indicates antiferromagnetic coupling in the system. Extended $\mathrm{x}$-ray absorption fine structure (EXAFS) also shows Co-Co bond in the precipitated solid (data not shown). 